\title{
EFFECT OF AGRICULTURE ON ENVIRONMENT
}

\author{
R Senaratne and M K TK Amarasinghe \\ Department of Crop Science \\ Faculty of Agriculture, Mapalana, \\ Kamburupitiya
}

The burgeoning population in this country is making increasing demands on agriculture. Consequently, there is mounting pressure on the natural resource base, particularly on land for increased food production. Failure to adopt appropriate soil and water conservation practices in agriculture has resulted in considerable soil erosion and land degradation, rendering a large extent of agricultural lands marginal and unproductive. Due to demographic pressure, agriculture is being extended even to sloping lands, causing heavy soil erosion. Moreover, shifting cultivation has continued unabated, further dwindling the forest cover, which has already reached a threshold value. With the advent of improved varieties, large quantities of agrochemicals such as inorganic fertilizers, insecticides, herbicides, fungicides etc. are being released to the environment. Many of farmers use pesticides indiscriminately polluting the soil, water and the food they produce, causing serious environmental and health problems.

Some major consequences of improper agricultural practices are the loss of soil fertility, land degradation, siltation of rivers and reservoirs, occurrence of flash floods, eutrophication of water bodies with attendant reduction in hydro-power generation, loss of biodiversity, emissions of green house gases such as $\mathrm{CO}_{2}$ and $\mathrm{NO}_{\mathrm{x}}$, which have far-reaching environmental, social, economic and political implications. The major causes of agriculture-related environmental problems, their effects and consequences and measures to mitigate them are discussed. 